\title{
Myeloid Leukemia Associated with Down Syndrome
}

National Cancer Institute

\section{Source}

National Cancer Institute. Myeloid Leukemia Associated with Down Syndrome. NCI

Thesaurus. Code C43223.

Acute myeloid leukemia or myelodysplastic syndrome occurring in children with Down syndrome. The acute myeloid leukemia is usually an acute megakaryoblastic leukemia, and is associated with GATA1 gene mutation. 